\title{
Sustentabilidade e suas Dimensões nas Ações da Secretaria do Meio Ambiente: Percepção da População do Centro da Cidade de Milagres-CE
}

\author{
Tátchyla Karinne Laurentino dos Santos ${ }^{l}$; Ana Isabel Calixto Donelardy ${ }^{2}$
}

\begin{abstract}
Resumo: Atualmente tem-se discutido muito sobre as questões de responsabilidade socioambiental, efetuada tanto pelo setor público, quanto o privado. Por este motivo, o presente artigo tem por objetivo geral, verificar como a população vê as ações da secretaria de meio ambiente da cidade de Milagres-CE se relacionarem com a sustentabilidade local. A pesquisa deste estudo é de abordagem quantitativa e de cunho descritivo. Sendo realizada uma pesquisa de opinião pública para captar a percepção das pessoas, com relação às ações da secretaria em tese. A pesquisa foi aplicada no centro comercial da cidade de Milagres-CE. O instrumento de coleta de dados utilizado foi um questionário contendo 10 perguntas, distribuídas entre abertas e fechadas, aplicadas ao público por acessibilidade e conveniência. Os resultados obtidos foram que a população da referida cidade desconhecem as ações da secretaria do meio ambiente, apontando a inexistência de práticas socioambientais.
\end{abstract}

Palavras-Chave: Sustentabilidade. Dimensões. Secretaria do Meio Ambiente.

\section{Sustainability and its Dimensions in the Actions of the Department of the Environment: Perception of the Population of Milagres City, State of Ceará}

\begin{abstract}
Now it has been discussing a lot on the subjects of responsibility socio-environmental, made so much by the public section, as the private. For this reason, the present article has for general objective, to verify as the population sees the actions of the general office of environment of the city of Miracle-CE if they relate with the local sustainability. The research of this study is of quantitative approach and of descriptive stamp. Being accomplished a research of public opinion to capture the people's perception, regarding the actions of the general office in theory. The research was applied in the commercial center of the city of Miracle-CE. The instrument of collection of data used was a questionnaire containing 10 questions, distributed between open and closed, applied to the public for accessibility and convenience. The obtained results were that the population of the referred city ignores the actions of the general office of the environment, pointing the inexistence of practices socioenvironmental.
\end{abstract}

Keywords: Sustainability. Dimensions. Secretariat of the Environment.

\section{Introdução}

A melhoria ambiental é capaz de beneficiar a produtividade dos recursos e processos de

\footnotetext{
${ }^{1}$ Graduanda em administração, Centro Universitário Doutor Leão Sampaio, Juazeiro do Norte, Ceará, Brasil. E-mail: jonasgalvai1234@gmail.com;

${ }^{2}$ Mestra em desenvolvimento regional sustentável, Centro Universitário Doutor Leão Sampaio, Juazeiro do Norte, Ceará, Brasil. E-mail: anaisabel@leaosampaio.edu.br.
}

163 Id on Line Rev. Mult. Psic. V.12, N. 42, Supl. 1, p. 163-179, 2018 - ISSN 1981-1179
Edição eletrônica em http://idonline.emnuvens.com.br/id 
uma organização com a economia de materiais e a diminuição e resíduos sólidos, podendo gerar ganhos econômicos devido à substituição, reutilização ou reciclagem dos insumos da produção e um menor consumo de energia ao longo dos processos (BARBIERI, 2011).

Para Aligleri (2011) toda iniciativa de negócio tem um impacto sobre o lucro, sociedade e meio ambiente, dessa forma, o desempenho inadequado e a falta de políticas bem elaboradas de cunho econômico, social e ambiental podem apresentar implicações organizacionais, acarretando prejuízos materiais e morais de modo a aumentar os custos, perder oportunidades de mercado, provocar escassez de recursos problemas sociais.

Considerando a sustentabilidade como uma ação socioambiental, que promove o bemestar social e permite desenvolvimento sustentável, com menos danos ao meio ambiente, mais igualdade social e geração de renda, busca-se saber: De que modo às práticas socioambientais da Secretaria de Meio Ambiente de Milagres-CE influenciam na sustentabilidade?

Para responder esta problemática, o artigo objetiva de modo geral verificar como a população vê as ações da Secretaria de Meio Ambiente da cidade de Milagres-CE se relacionarem com a sustentabilidade local. Especificando em definir Secretaria de Meio Ambiente, sua criação e políticas; compreender as dimensões da sustentabilidade e identificar as práticas ambientais executadas pela secretaria do meio ambiente que impactam na sustentabilidade do município. O artigo justifica-se por buscar compreender ações e práticas sustentáveis utilizadas em Milagres-CE, através da secretaria de meio ambiente, como também deixar registros para que futuros gestores possam utilizar-se deste estudo como fonte de pesquisa, visando melhorias ambientais.

\section{Fundamentação Teórica}

\section{Gestão Ambiental e Problemas Ambientais}

O uso do meio ambiente de forma errônea para obter recursos naturais provocou sérios problemas ambientais, principalmente após a revolução industrial, que teve um alto índice na necessidade de produção em escala, na sequencia houve em todo o planeta a exploração dos recursos naturais, aumento na quantidade de resíduos sólidos, desmatamento, poluições, 
desertificações e extinção de inúmeras espécies da fauna e flora (NOBEGRA, 2013).

Para solucionar os problemas ambientais necessita de uma postura dos empresários, sociedade e governo, considerando o meio ambiente como ponte de discussão, adotando decisões que possam contribuir para a ampliação da capacidade de suporte do planeta, ou seja, que possam ser utilizada pelas empresas em seus planejamentos administrativos, comunidade com o despertamento da consciência sustentável e governo na criação de mecanismo de ecoeficiência (BARBIERI, 2011).

A gestão ambiental pode ser definida de várias maneiras, dependendo do objetivo que busca qualificar, destacando que é o principal instrumento para se obter um desenvolvimento sustentável, podendo ser denominada como expressão utilizada para se relacionar com a gestão empresarial responsável em evitar os problemas ambientais (DIAS, 2011). Barbieri (2011) aponta a gestão ambiental como diretrizes e atividades administrativas ou operacionais, que tem como objetivo fornecer efeitos positivos sobre o meio ambiente, reduzindo danos causados pelas ações humanas.

Tachizawa (2005) apresenta a gestão ambiental como um importante instrumento gerencial para a capacitação e criação de estratégias competitivas, considerando a valorização da comunidade, reconhecimento profissional e aspectos ambientais e de capitais, sendo necessário o desenvolvimento de um sistema para a implantação da gestão ambiental.

\section{Sistema de Gestão Ambiental}

Um Sistema de Gestão Ambiental - SGA é compreendido por um conjunto de normas, práticas, ações ou projetos voltados ao desenvolvimento sustentável de uma empresa ou região, onde todos os processos são planejados, organizados, registrados e controlados para a execução, existindo normas legais para implantar um sistema de gestão ambiental, como estudos sobre viabilidade, ecoeficiência e certificação (TACHIZAWA, 2005).

O sistema de gestão ambiental possibilita às organizações uma melhor condição de gerenciamento para os aspectos de impactos ambientais, políticas de cunho social e geração de lucro, podendo interagir na mudança de atitudes e na cultura da organização (DIAS, 2011). A figura 01 apresenta as fases de uma implantação de um SGA. 
Figura 01: Fases de um Sistema de Gestão Ambiental.

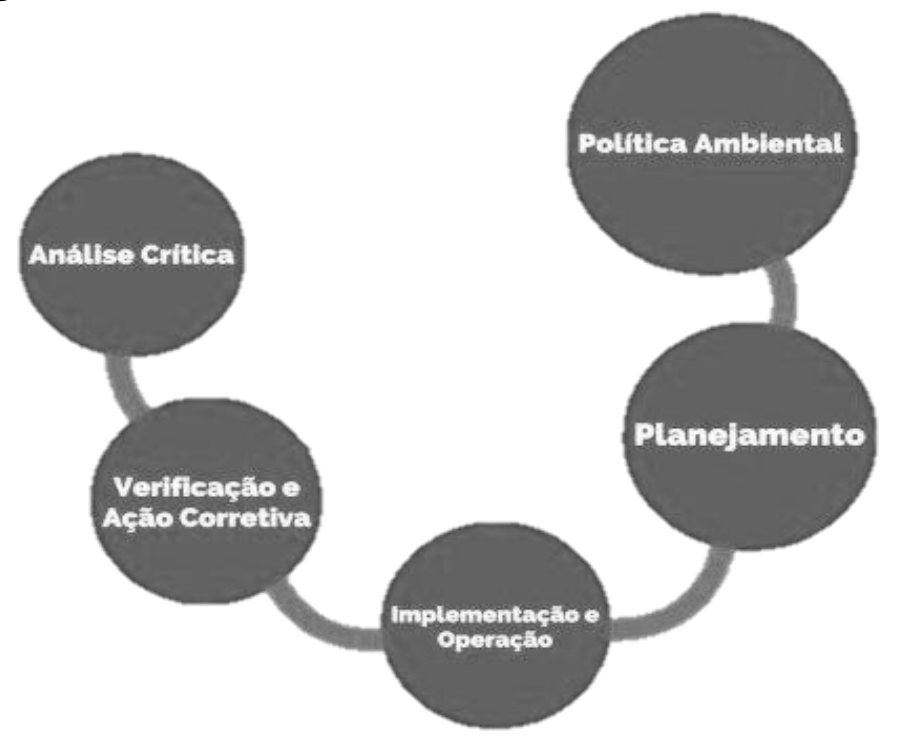

Fontes: Adaptado de Silva, Souza e Leal (2012).

Na figura 01, a fase inicial do sistema de gestão ambiental começa com a criação de uma política ambiental, que é um documento elaborado pela organização, onde estabelece uma estrutura com ações, objetivos e metas socioambientais. Em seguida acontece o planejamento, englobando as estratégias a serem implantada na empresa, salientando que a norma técnica da ISO 14000 solicita a formulação de um plano de política ambiental. Depois acontece a implantação e operação, voltado a atender o que está previsto na política, metas e objetivos, efetivação por meio da estrutura organizacional, treinamento, comunicação e controle (SILVA; SOUZA; LEAL, 2012).

Vale ressaltar que a aplicação ou implantação de um sistema consiste na redução de custos e desperdícios, incentivo a comercialização de produtos recicláveis, responsabilidade social e geração econômica, considerando a possibilidade de ser aplicável em qualquer empresa, seja esta de pequeno, médio ou grande porte, a depender do tipo de negócio (TACHIZAWA, 2005).

Considerando a figura 01 e de acordo com Silva, Souza e Leal (2012), a fase de verificação e ação corretiva, corresponde ao monitoramento dos processos do sistema, melhorando e adequando cada meta e objetivo, por meio de uma auditoria, excluindo aspectos não desejáveis. Na fase final ocorre à análise crítica, sendo este momento após a auditoria, 
aonde existe a identificação das possíveis alterações na política ambiental do SGA.

É necessário pautear que para inseri um sistema de gestão ambiental dentro de um contexto empresarial ou governamental, precisa-se entender sobre a sustentabilidade e suas dimensões (ALIGLERI, 2011).

\section{Sustentabilidade e suas Dimensões}

Tem-se falado muito sobre sustentabilidade nos últimos tempos, no entanto o real significado deste termo ainda é desconhecido para muito, levando em consideração os variados contextos da sociedade (VEIGA, 2009).

Conforme Philippe (2010) a sustentabilidade é a capacidade de se auto sustentar, especificando por manter um processo produtivo constante, utilizando os recursos naturais disponíveis e agregando atividades corretas na forma de manusear determinados recursos, havendo um equilíbrio entre a necessidade em produzir e a quantidade disponível.

Deste modo, partindo do pressuposto da sustentabilidade, o desenvolvimento sustentável passa a ser caracterizado como a facilidade de suprir as necessidades presentes sem afetar a habilidade das gerações futuras em suprirem as próprias necessidades (BARBIERI, 2011). Na sustentabilidade existem dimensões alinhadas ao meio econômico, ambiental, social, ética, política, jurídica, cultural e territorial, conforme ilustradas na figura 02 , apontadas por Dias (2011) e Sachs (2009).

A figura 02 ilustra o sincronismo das dimensões da sustentabilidade para se chegar ao desenvolvimento sustentável. Dias (2011) cita apenas três dimensões, econômica, social e ambiental, contudo Sachs (2009) acopla outras cinco dimensões, a ética, política, jurídica, cultural e territorial.

Segundo Freitas (2012) a dimensão social da sustentabilidade entende-se por a relação da diversidade e promoção da autonomia dos grupos sociais ou populacionais, no sentido de analisar a subsistência, submetendo a resolução pacífica de conflitos e convivência da sociedade, acolhendo os direitos fundamentais, como o amparo aos menos favorecidos ou a funcionários de determinada empresa, por exemplo. 
Figura 02: Dimensões da Sustentabilidade.

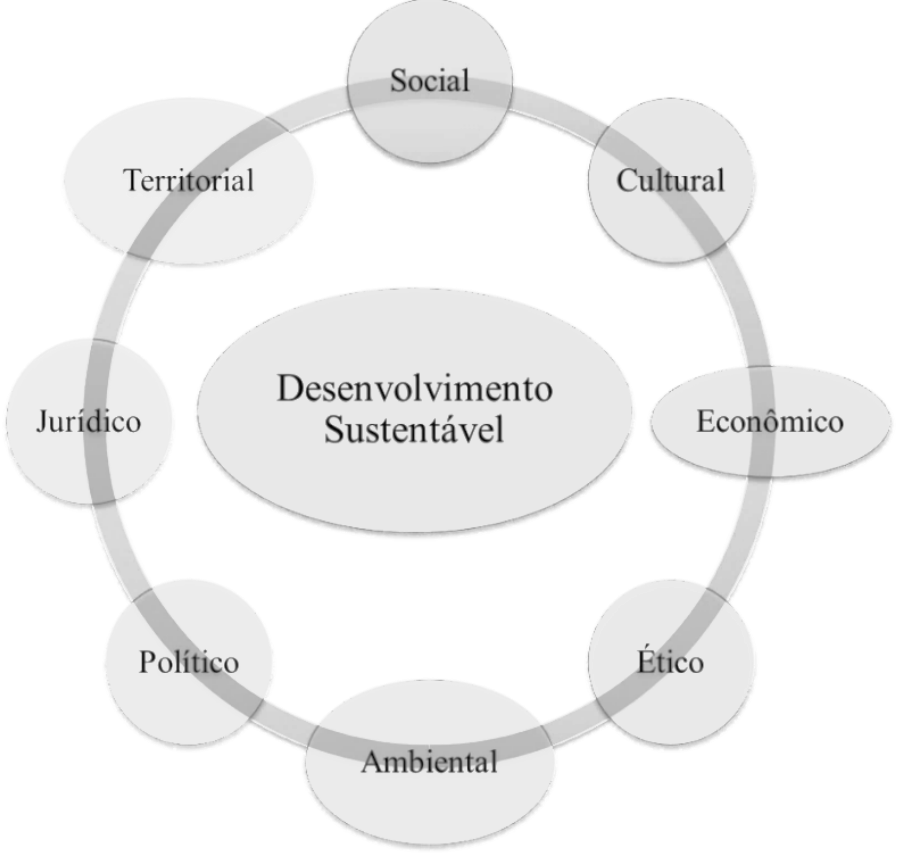

Fonte: Adaptação de Dias (2011) e Sachs (2009).

Sachs (2009) relata que deve existir uma igualdade na distribuição de renda sendo da forma mais justa possível para as pessoas, por intermédio de serviços prestados, enfatizando a busca por uma qualidade de vida plena. Considerando as desigualdades como um problema que emerge na sociedade, tornam-se essenciais atitudes favoráveis que venham a contribuir para a minimização das dificuldades sociais, em especial nas comunidades carentes, salientando a viabilização de oportunidades empregatícias, combates as práticas de exclusão, respeito à diversidade e construção da cidadania pelo governo e empresas (SILVA; SOUZA; LEAL, 2012).

A dimensão cultural para Freitas (2012) remete às questões de valorização as tradições e manifestações artríticas de um povo em determinada região, mencionado a empresa como força propulsora do equilíbrio, autonomia, inovação e capacidade de elaborar projetos integrados cultura do lugar onde está localizado o empreendimento.

Silva, Souza e Leal (2012) apresentam a dimensão cultural como a promoção da diversidade embasada nas memórias das comunidades, identidade e expressão de um lugar, 
especialmente daquelas que identifiquem às raízes históricas na construção de um povo, em função disto, as organizações necessitam fundir meios que valorize ou conserve o patrimônio histórico material e imaterial da região que estão situados.

Conforme Dias (2011) a dimensão econômica das organizações obtém importância na atuação financeira, almejado gerar uma concepção na qualidade de vida das pessoas, crescimento econômico com mentalidade no resultado do capital, mas com um olhar na preocupação ambiental e equilíbrio dos empreendimentos.

Neste contexto Sachs (2009) afirma que no crescimento econômico, necessita haver uma estabilidade entre os instrumentos de modernização constante, geração de renda, melhorias da economia e autonomia ao desenvolver uma estrutura equilibrada para a empresa, sociedade, governo e meio ambiente.

A dimensão ética tem como finalidade orientar os seres humanos na forma de pensar e agir, no que diz respeito à solidariedade ao executar responsabilidades ambientais e sociais, deixando um legado positivo, destacando que quanto maiores avanços existir na ciência ou tecnologia, mais as pessoas passaram a se desligar do mundo, assim a percepção da ética concebe a necessidade e os meios de ligar o homem e natureza (FREITAS, 2012).

A dimensão ambiental, na concepção de Dias (2011) ocorre quando empresas passam a preocuparem-se com a qualidade dos processos produtivos, levando em conta uma produção limpa, melhorias no desenvolvimento de um modelo sustentável, respeito ambiental e conservação dos recursos naturais, pauteando que as organizações são responsáveis, em partes, pelos problemas ambientais, como poluição, desertificação, desmatamento e extinção de inúmeras espécies da fauna e flora.

Ponderam na dimensão ambiental as inúmeras intervenções governamentais, sociais e empresariais, quanto à prudência na utilização dos recursos naturais, sinalização na importância de precaver as formas de ocupar áreas de proteção ambiental, consolidação de projetos voltados à economia verde, preservação, reciclagem e criação de técnicas para manusear recursos para a produção, onde não afete a biodiversidade ou agrave a qualidade de vida das pessoas (SILVA; SOUZA; LEAL, 2012).

De acordo com Freitas (2012) nas dimensões política e jurídica da sustentabilidade, existe uma abrangem nos direitos da regulamentação e amparo governamental ou legislativo do direito a vida presente ou futura, tendo a preocupação de proteger a prerrogativa ambiental, 
além de oferecer tratamentos e remédios gratuitos para os carentes, renda justa, ambiente digno e alimentação adequada sem excessos dos químicos perniciosos.

Sachs (2009) fomenta que a dimensão política está ligada a criação de mecanismos que incrementem ou motivem a participação da sociedade e empresas nas tomadas de decisões, respeito os direitos de todos e conservação do espaço histórico, social, cultural e ambiental, paralelamente, a dimensão jurídica vem reger os princípios morais e éticos, no sentido humano e ambiental, entrelaçado regras a serem seguidas na promoção do bem-estar e qualidade de vida.

A dimensão territorial refere-se à responsabilidade pública e privada com o espaço ocupado, ou seja, com o território onde empresas e governo estão localizados, tendo a ideia de investimentos públicos, saneamento básico, conservação da biodiversidade local, estratégias ambientais, melhorias urbanísticas e desenvolvimento humano na comunidade, partindo do trabalhando em conjunto, induzindo ao crescimento local e a comodidade social ou ambiental (FREITAS, 2012).

\section{Constituição da Secretaria de Meio Ambiente}

Com a participação brasileira na Conferência das Nações Unidas para o Meio Ambiente, realizada em Estocolmo em 1972, proporcionou um importante passo no avanço das questões ambientais no Brasil, despertando o interesse de órgãos públicos e de autoridades na intensificação dos processos legislativos para a busca da proteção e preservação do meio ambiente (MACHADO, 2006).

No ano 1973, por intermédio do decreto de número $73.030 / 73$, artigo. $1^{\circ}$, foi criada a Secretaria Especial do Meio Ambiente (SEMA), com a responsabilidade de orientar e conservar o meio ambiente, com o uso racional dos recursos naturais (SILVA, 2004). As competências outorgadas da SEMA, estão voltadas conduzir e administrar os assuntos pertinentes ao meio ambiente de uma forma integrada, inclusive, influenciar as normas e incentivos fiscais (FREITAS, 2001). 
O pioneirismo do meio ambiente dentro da Constituição Federal ocorreu em 1988, a partir de então, mudanças foram realizadas, em função de atender as demandas e problemas voltados a biodiversidade brasileira (SILVA, 2004).

Conforme Machado (2006), a secretaria do meio ambiente possui competências e atributos para o funcionamento legal das atividades, por exemplo, planejar, coordenar, avaliar, executar e controlar ações, que visem à proteção, conservação, melhorias e responsabilidade nos aspectos socioambientais.

\section{Metodologia}

O presente artigo contou com fontes de pesquisa bibliográfica. Possuindo abordagem quantitativa, sendo de natureza descritiva (CRESWELL, 2010). Quanto o meio utilizado para este artigo, optou-se por um estudo de opinião pública, por se tratar da busca em conhecer as atitudes e pontos de vista das pessoas sobre algum assunto (ALMEIDA, 1996).

A pesquisa foi realizada entre os dias 26 e 27 de outubro de 2018, no centro da cidade de Milagres-CE. A referida cidade esta localizada as margens da BR 116 há 487 km da capital Fortaleza. É conhecida por a Terra dos Coqueirais e possui população estimada em 2017 de 28.231 habitantes. A referida cidade contempla uma cultura voltada aos grupos de congos, festas juninas e expressão de religiosidade, segundo dados do Instituto Brasileiro de Geografia e Estatística - IBGE (2016).

Participaram da pesquisa 200 pessoas, sendo 58\% mulheres e $42 \%$ homens, que estavam no centro da cidade em estudo, participando por acessibilidade e conveniência (SEVERINO, 2016). A idade dos entrevistados pauteou entre 18 a 56 anos. Foi aplicado um questionário contendo 10 perguntas distribuídas em abertas e fechadas. Em seguida aconteceu a tabulação dos dados por intermédio do software Excel. Na sequência ocorreu a análise e discussão dos resultados encontrados. 


\section{Análise e Discussão dos Resultados}

Visando conhecer a percepção da população do centro da cidade de Milagres-CE, acerca da sustentabilidade e suas dimensões nas ações da secretaria do meio ambiente, foi realizada uma pesquisa de opinião nos dias 26 e 27 de outubro de 2018, no centro comercial da cidade em estudo. Participaram do estudo 200 pessoas, cujo gênero totalizou em 58\% feminino e $42 \%$ masculino. A faixa etária dos entrevistados oscilou em $40 \%$ com idade entre 18 a 25 anos, 30\% entre 26 a 35 anos, 16\% entre 36 a 45 anos, 12\% entre 46 a 55 anos e 2\% acima de 56 anos.

$\mathrm{Na}$ sequência da pesquisa foram feitas perguntas voltadas ao conhecimento sobre a existência da secretaria do meio ambiente da cidade, percepção dos serviços prestados, melhorias na secretaria visando à sustentabilidade no município, identificação da coleta de lixo e opiniões a respeito das práticas voltadas às dimensões social, ambiental e econômica. $\mathrm{O}$ gráfico 01 aponta o conhecimento acerca da secretaria do meio ambiente da cidade em estudo.

Gráfico 01: Conhece a Secretaria do Meio Ambiente da Cidade de Milagre-CE.

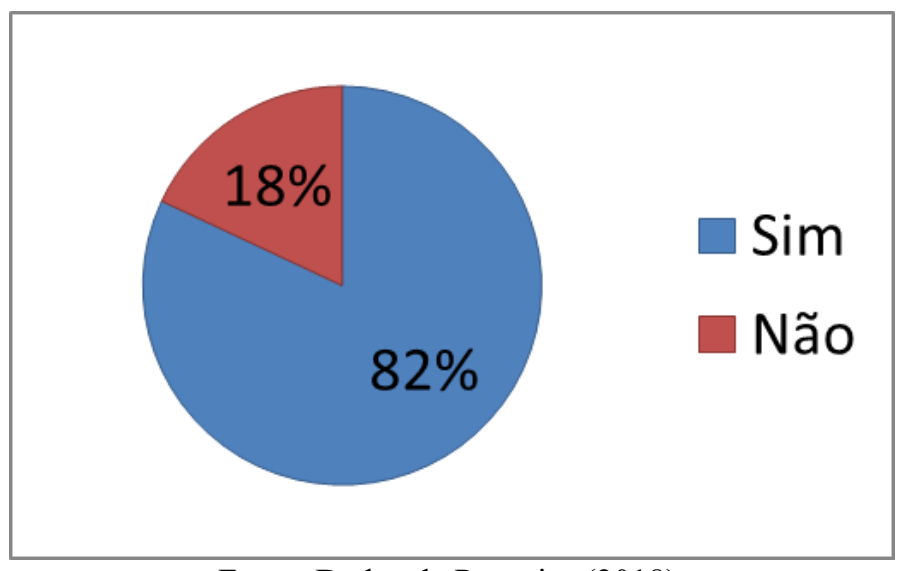

Fonte: Dados da Pesquisa (2018).

O gráfico 01 mostra que $82 \%$ dos participantes falaram que não conhecem a secretaria do meio ambiente da cidade de Milagres-CE. Apenas 18\% conhecem a secretaria em questão. É notório que os milagrenses desconhecem esta entidade, levando a entender que não há divulgações das ações executadas ou sobre a real existência. O gráfico 02 apresenta a percepção dos entrevistados, sobre as campanhas e projetos socioambientais executadas. 
Gráfico 02: Conhece Alguma Campanha ou Projeto Socioambiental Executado na Cidade.

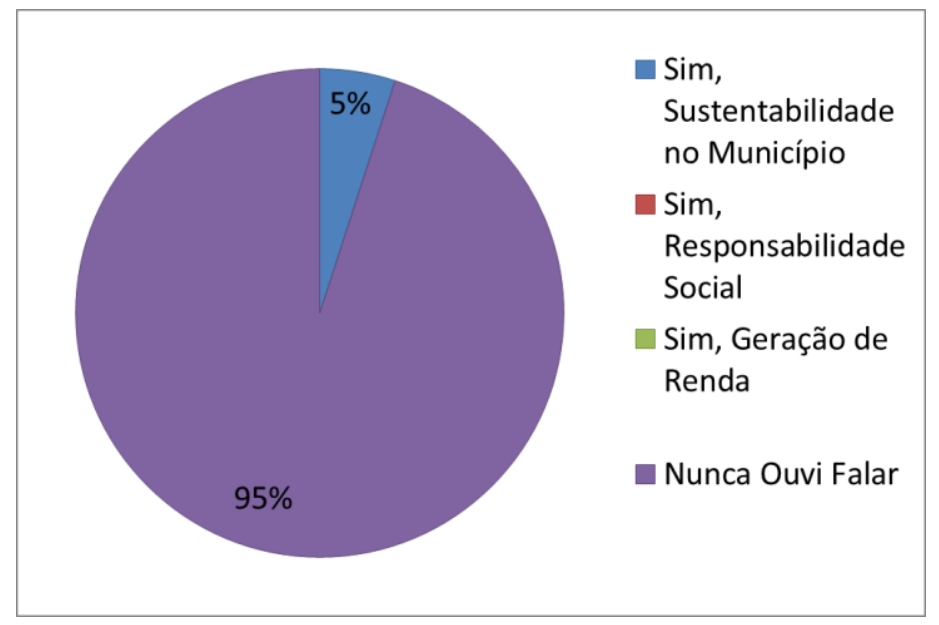

Fonte: Dados da Pesquisa (2018).

Como mencionado, o gráfico 02 aponta o conhecimento dos participantes sobre as ações socioambientais executadas na cidade de Milagres-CE. 95\% afirmam que nunca ouviu falar das referidas ações. O interessante é que $5 \%$ pontuam conhecer campanhas e projetos voltados à sustentabilidade do município.

Logo, pode-se considerar que população desconhecem as campanhas e projetos executados pela secretaria do meio ambiente, visto a inexistência de divulgadas das mesmas. A responsabilidade social e a geração de renda não foram apontadas como ações praticadas na cidade. Todas as ações citadas na pergunta englobam as três dimensões da sustentabilidade, a social, ambiental e econômica, ditas por Dias (2011), Sachs (2009) e Freitas (2012). 
Gráfico 03: Percepção Sobre os Serviços Prestados pela Secretária do Meio Ambiente.

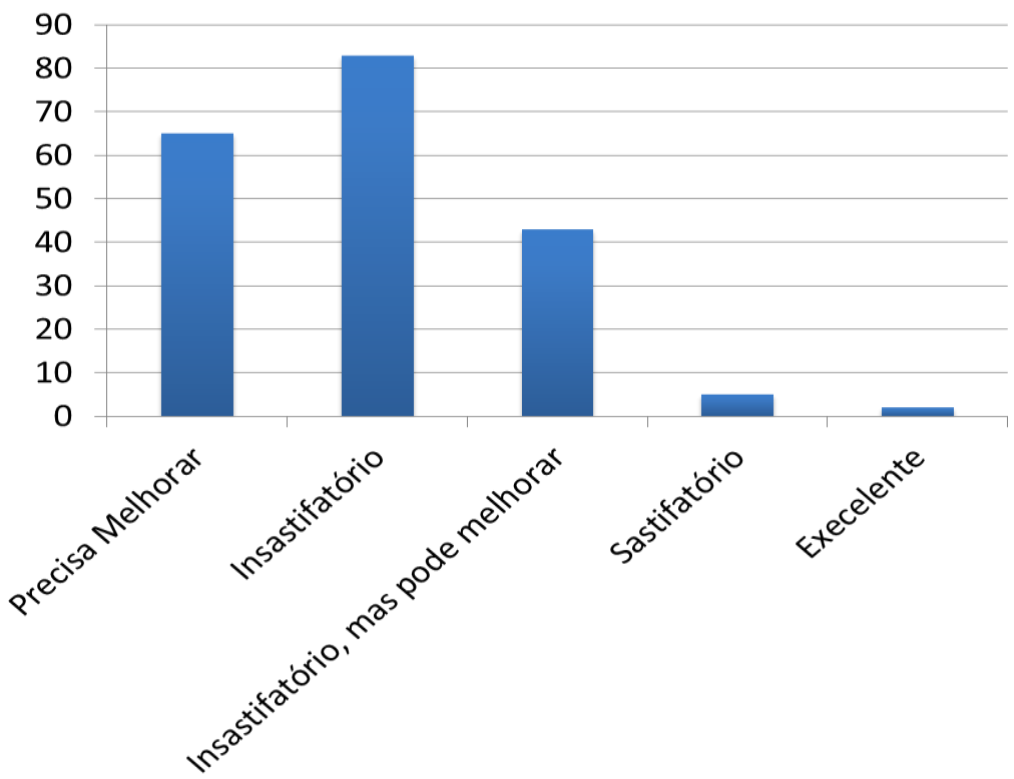

Fonte: Dados da Pesquisa (2018).

O gráfico 03 apresenta a percepção dos entrevistados sobe os serviços prestados pela secretaria do meio ambiente para a população milagrense. A maioria destaca que os serviços são insatisfatórios, mas podem melhorar, na opinião de outros. Em suma, estes serviços não estão condizentes com o que a população espera ou deseja, havendo então a necessidade de melhorias neste serviço prestado, tanto para o suporte ambiental, apoio as comunidades e fortalecimento da economia local. Alguns ainda colocam os serviços ofertados como satisfatório e excelente.

Em termos de saber se os participantes enxergavam alguma prática sustentável efetuada no município, foi perguntado: Você consegui identificar alguma coleta seletiva do lixo na cidade de Milagres-CE? Analisando as respostas fornecidas, conclui-se que $87 \%$ dos entrevistados não identificam com nitidez a coleta seletiva.

Contudo, $13 \%$ falaram que enxergam a coleta mencionada na cidade. Neste caso, podese afirmar a possibilidade de uma inexistência da coleta seletiva ou a realização parcial desta. Considerando também a falta de divulgações dessa ação. 
Gráfico 04: Campanhas de Reflorestamento e Educação Ambiental.

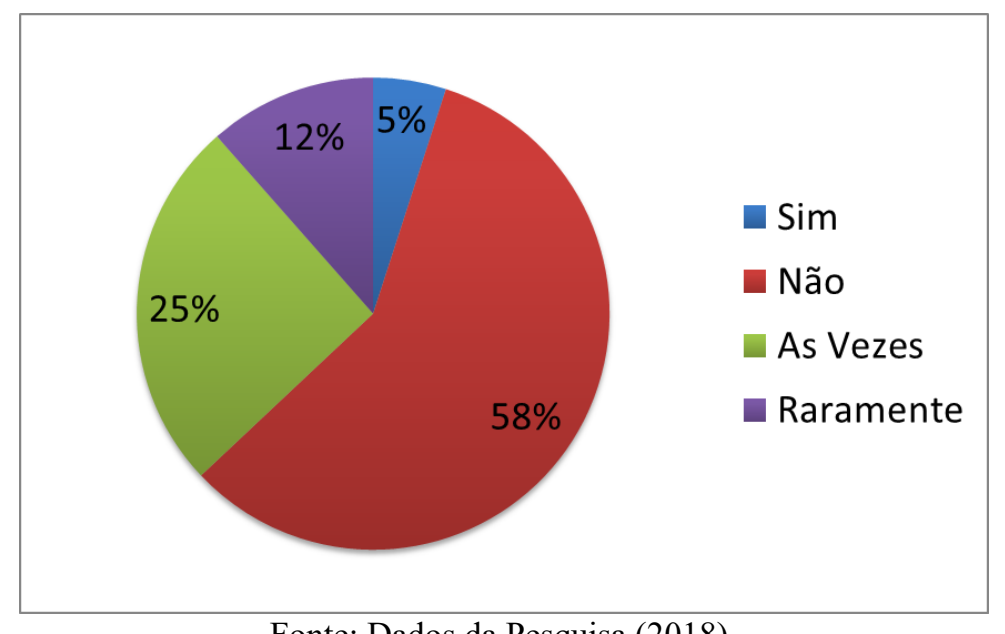

Fonte: Dados da Pesquisa (2018).

No gráfico 04, está descrita a percepção dos participantes acerca das campanhas de reflorestamento e educação ambiental, realizada pela secretaria do meio ambiente, no âmbito da dimensão ambiental da sustentabilidade. 58\% disseram que não há realização de nenhum tipo de campanhas, 25\% identificaram "às vezes" e 12\% citaram "raramente". Apenas 5\% pontuaram que sim. Nota-se então, que a secretaria não atende as exigências ou intervenções da dimensão em tese, mencionadas por Silva, Souza e Leal (2012).

Gráfico 05: Conservação dos Espaços Públicos, Prmoção da Qualidade de Vida da População, Movimentos Culturais e Geração de Renda.

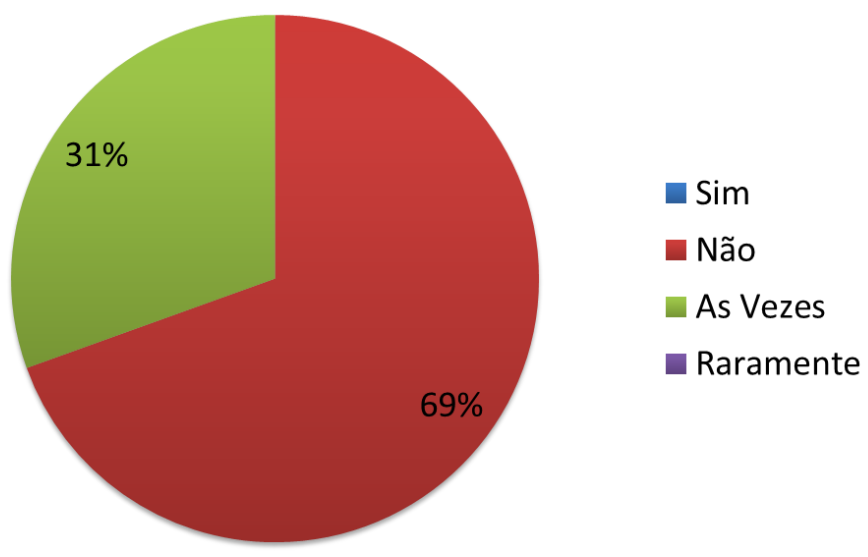

Fonte: Dados da Pesquisa (2018). 
O gráfico 05 mostra a opinião dos participantes da pesquisa, sobre a perspectiva da dimensão social, cultural e econômica da sustentabilidade. É perceptível que $69 \%$ afirmam que não existe uma conservação dos espaços públicos, promoção da qualidade de vida para a população e nem movimentos culturais ou geração de renda, por parte da secretaria do meio ambiente. Outros (31\%) colocam que "às vezes" há alguma ação.

Entende-se então, que há uma deficiência nestas dimensões, citadas por Sachs (2009), Dias (2011) e Freitas (2012). Visto que os participantes, em maioria, apontam que não ocorre nenhuma destas ações no município. Sendo necessário criar projetos para atender estas dimensões da sustentabilidade, no âmbito de responsabilidade socioambiental da secretaria.

O quadro 01, apresenta os pontos a serem melhorados pela secretaria do meio ambinte na cidade de Milagres-CE, na opnião dos participantes.

Quadro 01: O que precisa ser melhorado.

\begin{tabular}{|c|c|}
\hline Número de Pessoas & Ponto a ser Melhorado \\
\hline 146 & Acabar com o lixão e construir um aterro sanitário \\
\hline 36 & Reflorestamento no município \\
\hline 18 & Coleta seletiva no município \\
\hline
\end{tabular}

Fonte: Dados da Pesquisa (2018).

Analisando o quadro 01, o ponto principal a ser melhorado seria a criação de um aterro sanitário na cidade, levando em conta que o município ainda conta com um lixão a céu aberto. Vale salientar que existe Lei Federal que regulamenta a criação de aterros sanitários em todo o país até 2020. O reflorestamento e a coletada seletiva aparecem na sequência como ponto de mudança ou implantação. Ambos aparecem como inexistente na cidade, considerando o gráfico 04 e pergunta realizada sobre coleta seletiva em Milagres-CE, respectivamente.

É nítido que a secretaria do meio ambiente, está deixando a desejar, no sentido de aplicabilidade das dimensões da sustentabilidade nas ações executadas. Neste caso, a cidade não conta com uma gestão ambiental, descrita por Tachizawa (2005), Barbieri (2011) e Aligleri (2011). 
Na constituição das secretarias ambientais, Machado (2006) fomenta que a secretaria do meio ambiente possui competências e atributos para o funcionamento das atividades, partindo do pressuposto do planejamento, coordenação, avaliação, execução e controle das ações, que visam à preservação, conservação e responsabilidade socioambiental.

\section{Considerações Finais}

Perante os procedimentos teóricos e metodológicos utilizados neste estudo, pode-se considerar que a gestão ambiental é um conjunto de ações voltadas para a sustentabilidade, nos aspectos ambientais, sociais e econômicos. Estes aspectos, também são conhecidos por dimensões da sustentabilidade, que visam à capacidade de se auto sustento do planeta. As esferas pública ou privada podem implantar ações para fomentar a sustentabilidade local.

Assim, este artigo teve por objetivo geral verificar como a população vê as ações da secretaria de meio ambiente da cidade de Milagres-CE se relacionarem com a sustentabilidade local, onde foi identificada a inexistência de ações, campanhas e projetos socioambientais, como também a falta de divulgações das poucas ações executadas na cidade.

Este objetivo tinha como proposta, responder a problemática do estudo. Que era saber de que modo às práticas socioambientais da secretaria de meio ambiente de Milagres-CE influenciam na sustentabilidade. Chegando a conclusão que não influencia, visto a falta de ações, previstas nas dimensões, para se chegar à sustentabilidade. Vale apontar, que os participantes mencionam a necessidade de melhorias na conduta dos serviços prestados pela secretaria, em quanto, entidade pública.

Pode-se destacar ainda, que os entrevistados desconhecem a secretaria do meio ambiente do município em questão. É perceptível com a realização da pesquisa, que os participantes almejam a criação de um aterro sanitário para o fim do lixão a céu aberto, coleta seletiva de lixo e reflorestamento.

A pesquisa mostra o cenário atual dos aspectos inerentes à sustentabilidade na cidade de Milagres-CE, na opinião dos participantes. Ficam então abertas para futuros estudos, à criação de ferramentas que visem à implantação de uma gestão ambiental, canais de divulgações das ações já executadas e a realização de um planejamento estratégico na secretaria do meio 
ambiente. A partir destas ações, haverá então a possibilidade de criar um sistema de gestão ambiental no município.

\section{Referências}

ALIGLERI, Lilian Mara. Adoção de Ferramentas de Gestão para a Sustentabilidade e a sua Relação com os Princípios Ecológicos nas Empresas. p. 178. Tese de Doutorado: Universidade de São Paulo, 2011.

BARBIERI, José Carlos. Gestão Ambiental Empresarial: Conceitos, Modelos e Instrumentos. 2. ed. São Paulo: Saraiva, 2011.

CRESWELL, John. Projeto de Pesquisa: Métodos Qualitativo, Quantitativo e Misto. 3. ed. Porto Alegre: Artmed, 2010.

DIAS, Reinaldo. Gestão Ambiental: Responsabilidade Social e Sustentabilidade. 2. ed. São Paulo: Atlas, 2011.

FREITAS, Juarez. Sustentabilidade: Direito ao Futuro. 2. ed. Belo Horizonte: Fórum, 2012.

FREITAS, Vladimir Passos de. Direito Administrativo e Meio Ambiente. 3. ed. Curitiba: Juruá, 2001.

IBGE. População e Características Físicas de Milagres - Ceará. Disponível em: $<$ https://cidades.ibge.gov.br/brasil/ce/milagres/panorama>. Acesso em: 15 out. 2018.

MACHADO, Paulo Affonso Leme. Direito Ambiental Brasileiro. 14. ed. São Paulo: Malheiros, 2006.

NOBREGA, Ribeiro. Práticas Sustentáveis. 1. ed. João Pessoa: Moura Ramos, 2015.

PHILIPPI, Luiz Sérgio. A Construção do Desenvolvimento Sustentável. 3. ed. São Paulo: Manole, 2010.

SACHS, Ignacy. Caminhos para o Desenvolvimento Sustentável. 2. ed. Rio de Janeiro: Garamond, 2009.

SEVERINO, Antônio Joaquim. Metodologia do Trabalho Científico. 24. ed. São Paulo: Cortez, 2016.

SILVA, Antônio Sergio; SOUZA, José Gilberto; LEAL, Antônio Cezar. A Sustentabilidade e suas Dimensões como Fundamento da Qualidade de Vida. Artigo Científico, v. 1, n. 12, p. 22- 
42: Presidente Prudente, 2012.

SILVA, José Afonso da. Direito Ambiental Constitucional. 5. ed. São Paulo: Malheiros, 2004.

VEIGA, José Eli. Desenvolvimento Sustentável: O Desafio do Século XXI. 1. ed. Rio de Janeiro: Garamond, 2009.

TACHIZAWA, Takeshy. Gestão Ambiental e Responsabilidade Social Corporativa: Estratégias de Negócio na Realidade Brasileira. 4. ed. São Paulo: Atlas, 2005.

\section{Como citar este artigo (Formato ABNT):}

SANTOS, Tátchyla Karinne Laurentino dos; DONELARDY, Ana Isabel Calixto. Sustentabilidade e suas Dimensões nas Ações da Secretaria do Meio Ambiente: Percepção da População do Centro da Cidade de Milagres-CE. Id on Line Rev.Mult. Psic., 2018, vol.12, n.42, Supl. 1, p. 163-179. ISSN: 1981-1179.

Recebido: 02/11/2018;

Aceito: 05/11/2018 